\title{
Adipose Triglyceride Lipase (ATGL) Expression Is Associated with Adiposity and Tumor Stromal Proliferation in Patients with Pancreatic Ductal Adenocarcinoma
}

\author{
SHANE A. GRACE ${ }^{1}$, MARSHALL W. MEEKS ${ }^{1}$, YONGXIN CHEN ${ }^{1}$, MONA CORNWELL $^{1}$, XIANZHONG DING $^{2}$, \\ PING HOU $^{1}$, JOANNE K. RUTGERS ${ }^{3}$, SUSAN E. CRAWFORD ${ }^{1}$ and JIN-PING LAI ${ }^{1}$ \\ ${ }^{1}$ Department of Pathology, Saint Louis University School of Medicine, Saint Louis, MO, U.S.A.; \\ ${ }^{2}$ Department of Pathology, Loyola University Medical Center, Maywood, IL, U.S.A.; \\ ${ }^{3}$ Department of Pathology and Laboratory Medicine, Cedars-Sinai Medical Center, Los Angeles, CA, U.S.A.
}

\begin{abstract}
Background: Obesity is an established risk factor for the development of pancreatic ductal adenocarcinoma (PDAC). However, the pathophysiology of how increased adiposity increases the risk for PDAC has not been fully elucidated. Adipose triglyceride lipase (ATGL) is a lipase that catabolizes triglyceride hydrolysis and has been implicated in the development of breast cancer. We hypothesized that overweight patients with PDAC would demonstrate higher tumor ATGL expression compared to non-overweight patients with PDAC. Materials and Methods: Immunohistochemical analysis for ATGL expression was performed on PDAC tissues from 44 patients after Whipple procedure or distal pancreatectomy. Correlation of ATGL expression with clinicopathological features was evaluated. Results: A total of 23/44 (52.2\%) PDACs showed low level ATGL immunoreactivity, while 21/44 (47.8\%) showed a high level, with moderate to strong positive ATGL immunoreactivity in more than 50\% of the tumor cells. Chisquared testing revealed a statistically significant association between high ATGL expression and both BMI $>25 \mathrm{~kg} / \mathrm{m}^{2}$ $\left(\chi^{2}=5.74, p=0.017\right)$ and increased tumor stroma $\left(\chi^{2}=19.14\right.$, $p<0.001)$. Chi-squared testing failed to reveal a statistically significant association when comparing ATGL expression by lymph node metastasis, histological grade, tumor size, patient age, patient sex and presence of fat invasion. Conclusion: Our results suggest that increased ATGL expression is associated
\end{abstract}

This article is freely accessible online.

Correspondence to: Jinping Lai, MD, Ph.D., Department of Pathology, Saint Louis University, 1402 South Grand Blvd, St. Louis, MO 63104, U.S.A. Tel: +1 3145778475, Fax: +1 3145776132, e-mail: jinpinglai@slu.edu

Key Words: Adipose triglyceride lipase, ATGL, pancreatic ductal adenocarcinoma, PDAC, obesity. with increased adiposity and stromal proliferation in patients with PDAC, making it a possible key protein in how obesity increases the risk of PDAC.

Pancreatic ductal adenocarcinoma (PDAC) carries an extremely poor prognosis, with a 5-year survival rate of less than $6 \%$ in the United States (1). The low survival rate is due to the late stage at which patients are usually diagnosed, with only $20 \%$ of patients being eligible for tumor resection at the time of diagnosis (1). Several risk factors for PDAC are firmly established, such as chronic pancreatitis (2), cigarette smoking (3), family history of pancreatic cancer (4), and diabetes mellitus (5).

Both epidemiological and experimental studies have also linked obesity to the development of PDAC. In a large casecontrol study, Silverman et al. (6) showed obesity portends a $50-60 \%$ increased risk of PDAC in both men and women. Similarly, a pooled case-control analysis using data from the Pancreatic Cancer Cohort Consortium (PanScan) comparing 2170 PDAC cases to 2209 controls showed a positive association between increasing body mass index (BMI) and risk of PDAC [adjusted odds ratio (aOR) for the highest vs. lowest $\mathrm{BMI}$ quartile $=1.33,95 \%$ confidence interval $(\mathrm{CI})=$ $1.12-1.58, p<0.001$ (7).

The mechanism of how obesity increases PDAC risk is poorly understood. Previous studies have shown that increased peritumoral fat density promotes metastasis and increases mortality in patients with PDAC (8). Adipose triglyceride lipase (ATGL) is a lipase in adipose tissue that catabolizes the first step in triglyceride hydrolysis and is responsible for the release of free fatty acids. Another lipase called monoacylglycerol lipase has been shown to be overexpressed in human cancer cell lines and to promote in vivo tumor growth via 'feeding' cancer cells with free fatty acids (9). Previous studies of breast cancer demonstrated increased peritumoral ATGL expression in fat cells of obese 
patients compared to non-obese patients, suggesting that increased adiposity contributes to increased tumor growth (10). However, currently no studies have investigated the relationship between ATGL expression and obesity in patients with PDAC. We hypothesized that overweight patients with PDAC would demonstrate higher tumor ATGL expression compared with non-overweight patients with PDAC.

\section{Materials and Methods}

Patients and clinicopathological data. This study was approved by the Institutional Review Board at Saint Louis University (St. Louis, MO) (approval number 25281). Clinicopathological information was collected for each patient from 2010 to 2014 via retrospective review of the pathology database. Patient demographics included age, sex and BMI). A BMI over $25 \mathrm{~kg} / \mathrm{m}^{2}$ was considered overweight and BMI $\leq 25 \mathrm{~kg} / \mathrm{m}^{2}$ was considered non-overweight. We chose BMI of $25 \mathrm{~kg} / \mathrm{m}^{2}$ as a cutoff because we had very few patients with BMI >30 $\mathrm{kg} / \mathrm{m}^{2}(\mathrm{n}=4,9 \%)$. Tumor characteristics included size, histological grade, tumor $(\mathrm{T})$ stage, and nodal status. Tissue arrays were constructed using 33.1 and $20 \mathrm{~mm}^{2}$ of PDAC tumor tissue from 44 patients and used for immunohistochemistry of ATGL.

Immunohistochemistry (IHC). Analysis by IHC was performed on $4-\mu \mathrm{m}$ thick sections using antibodies for ATGL (Cell Signaling Technology, MA, USA) as previously described (Figure 1) (11). IHC stains were graded on a scale from 0 to 3 : score 0 represented absence of staining; score 1 represented $<30 \%$ of tumor cells with positive staining; score 2 represented between $30-50 \%$ of tumor cells with positive staining; and score 3 represented $>50 \%$ tumor cells with positive staining. Each specimen with a score $\geq 1$ was also given a density score. High ATGL expression was characterized as moderate-to-strong staining density present in more than $50 \%$ of the tumor cells. Additionally, each specimen was analyzed for the presence or absence of fat invasion by tumor. The amount of stroma within each tumor specimen was also scored on a scale from 0 to 3 , depending on the ratio of stroma to malignant glands: score 0 represented absence of stroma; score 1 represented a stroma/tumor cell ratio of $<30 \%$; score 2 represented a stroma/tumor cell ratio between $30-50 \%$; and score 3 represented a stroma/tumor cell ratio of $>50 \%$. Scoring of the immunostain was blindly performed by two board-certified gastrointestinal pathologists (JL and YC).

Statistical analysis. Statistical analyses were performed using SPSS software, version 23.0 (IBM Corp., Armonk, NY, USA). Correlation between ATGL expression and clinicopathological characteristics were evaluated by the chi-square test. $p$-Values less than 0.05 were considered statistically significant.

\section{Results}

Patient and tumor characteristics. Patient demographic and tumor characteristics are presented in Table I. ATGL levels were analyzed in a total of 44 patients with PDAC. The mean age of our study population was 66.5 years (range $=43-84$ years). The mean BMI was $24.2 \mathrm{~kg} / \mathrm{m}^{2}$ (median $=24.6 \mathrm{~kg} / \mathrm{m}^{2}$; range $=15.8-39.5 \mathrm{~kg} / \mathrm{m}^{2}$ ) and the mean tumor size was $3.5 \mathrm{~cm}$ (range=1.2-6.4 cm). The majority of the tumors were
Table I. Clinicopathological correlation of adipose triglyceride lipase (ATGL) expression in 44 patients with pancreatic ductal adenocarcinoma.

\begin{tabular}{|c|c|c|c|c|}
\hline Variable & $\begin{array}{c}\text { Low } \\
\text { ATGL, } \\
n\end{array}$ & $\begin{array}{c}\text { High } \\
\text { ATGL, } \\
\text { n }\end{array}$ & $\chi^{2}$ & $p$-Value \\
\hline Age at diagnosis (years) & & & 0.002 & 0.989 \\
\hline$\geq 65$ & 12 & 11 & & \\
\hline$<65$ & 11 & 10 & & \\
\hline Gender & & & 0.091 & 0.763 \\
\hline Male & 12 & 10 & & \\
\hline Female & 11 & 11 & & \\
\hline Body mass index $\left(\mathrm{kg} / \mathrm{m}^{2}\right)$ & & & 5.74 & 0.017 \\
\hline$>25$ & 6 & 13 & & \\
\hline$\leq 25$ & 17 & 8 & & \\
\hline Tumor size $(\mathrm{cm})$ & & & 0.878 & 0.349 \\
\hline$\geq 3.5$ & 12 & 8 & & \\
\hline$<3.5$ & 11 & 13 & & \\
\hline Nodal metastasis & & & 0.781 & 0.377 \\
\hline Yes & 4 & 6 & & \\
\hline No & 19 & 15 & & \\
\hline Tumor fat invasion & & & 0.71 & 0.400 \\
\hline Yes & 18 & 14 & & \\
\hline No & 20 & 10 & & \\
\hline Tumor score & & & 2.17 & 0.338 \\
\hline 1 & 7 & 4 & & \\
\hline 2 & 14 & 12 & & \\
\hline 3 & 2 & 5 & & \\
\hline Stroma score & & & 19.14 & $<0.001$ \\
\hline 1 & 5 & 1 & & \\
\hline 2 & 17 & 6 & & \\
\hline 3 & 1 & 14 & & \\
\hline
\end{tabular}

n, Number of patients.

moderately differentiated (G2) $(26 / 44,59 \%)$; a minority were well-differentiated (G1) $(11 / 44,25 \%)$ or poorly differentiated (G3) $(7 / 44,16 \%)$.

PDACs of overweight patients had higher ATGL expression compared to those from non-overweight patients. IHC analysis was performed to compare tumor ATGL expression in overweight patients (BMI $>25 \mathrm{~kg} / \mathrm{m}^{2}$ ) compared to nonoverweight patients (BMI $\leq 25 \mathrm{~kg} / \mathrm{m}^{2}$ ) (Table I). Six cases $(6 / 44,13.6 \%)$ showed negative-to-weakly positive ATGL staining in fewer than $30 \%$ of the tumor cells. Seventeen cases $(17 / 44,38.6 \%)$ showed weak-to-moderate ATGL expression in $30-50 \%$ of the tumor cells. Twenty-one cases $(21 / 44,47.8 \%)$ showed moderate-to-strong ATGL expression in more than $50 \%$ of the tumor cells. Twenty-three cases $(23 / 44,52.2 \%)$ with a score $1-2$ were considered to have low expression and $21(21 / 44,47.8 \%)$ were considered to have high expression. Chi-squared testing revealed a statistically significant association between high ATGL expression and BMI over $25 \mathrm{~kg} / \mathrm{m}^{2}$ ( $p=0.017$; Table I). 

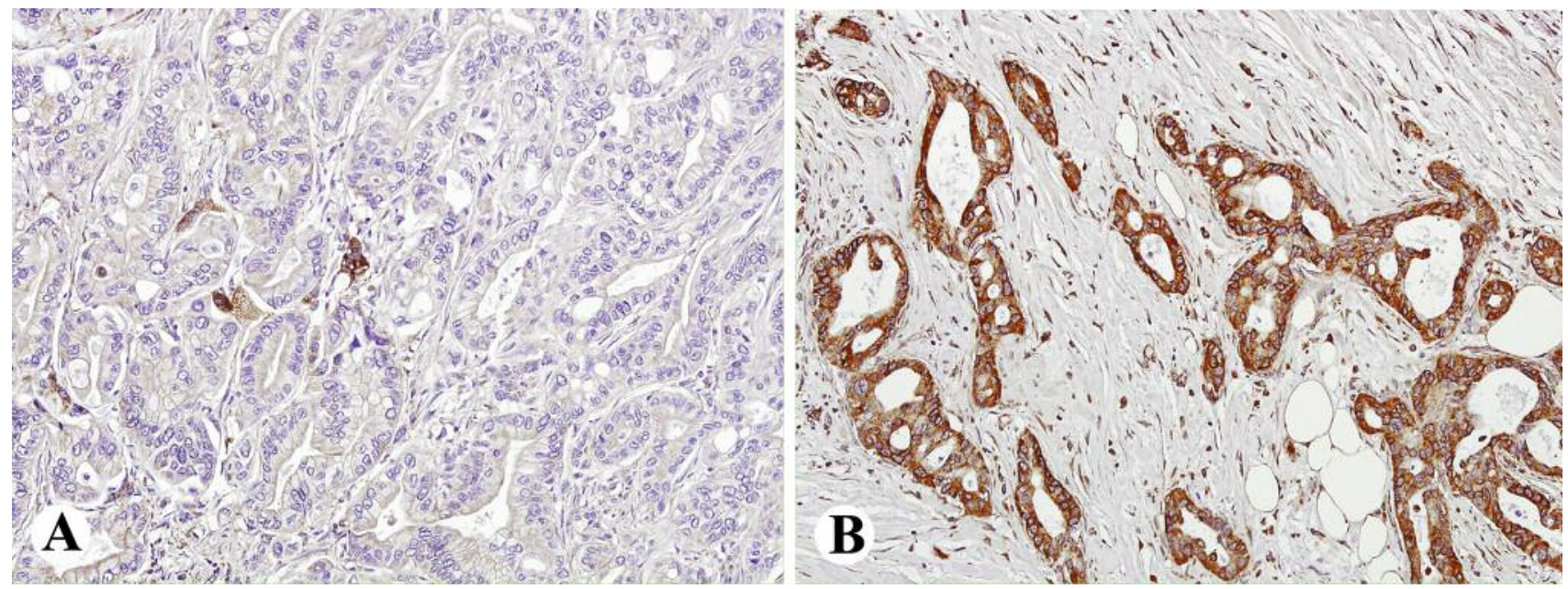

Figure 1. A: A case of moderately differentiated pancreatic ductal adenocarcinoma with minimal desmoplasia, showing essentially negative reactivity for antibody to adipose triglyceride lipase (ATGL). B: Another case of moderately differentiated PDAC with marked desmoplasia, showing a high level of ATGL immunoreactivity. Original magnification, $\times 200$.

PDACs with higher desmoplasia showed higher ATGL expression compared to PDACs with low desmoplasia. ATGL expression was compared between the PDACs with low desmoplasia (Figure 1A) and high desmoplasia (Figure 1B). Chi-squared testing revealed a statistically significant association between high ATGL expression and increased tumor stroma ( $p<0.001$; Table I).

IHC analysis was also performed to compare ATGL expression in tumors without fat invasion compared to those with. When tumors demonstrated fat invasion, ATGL grading was performed on the tumor cells directly contiguous to the fat cells rather than the whole tumor. Chi-squared testing failed to identify a statistically significant association between high ATGL expression and the presence of fat invasion $(p=0.400)$.

No statistically significant association was found when comparing ATGL expression by lymph node metastasis or histological grade $(p>0.05)$. Additionally, no significant association was found when comparing ATGL expression in tumors $<3.5 \mathrm{~cm}$ to tumors $\geq 3.5 \mathrm{~cm}$, patients older than 65 compared to those younger, or by patient sex $(p<0.05$; Table I).

\section{Discussion}

Adipose tissue is a complex endocrine organ that regulates fatty acid metabolism and secretes cytokines and hormones that affect distant targets. Strong evidence suggests that obesity is implicated in the etiology of many different cancer types, including PDAC $(12,13)$. Increased adiposity has also been shown to lead to poorer outcomes in a variety of cancer types. However, the pathophysiology behind how obesity increases risk and leads to poorer outcomes for pancreatic cancer has not been fully elucidated. ATGL is a lipase in adipose tissue that catabolizes the first step in triglyceride hydrolysis and is responsible for the release of free fatty acids. In a study of patients with breast cancer, Gnerlich $e t$ $a l$. found increased ATGL expression in the peritumoral and distant fat of obese patients compared to non-obese patients (10). As far as we are aware, the current study is the first to examine the relationship between tumor ATGL expression and PDAC. We found increased ATGL expression in the PDACs of overweight patients compared to non-overweight patients, suggesting that ATGL could be a key enzyme in explaining how obesity increases PDAC risk. Additionally, we found an association between tumor ATGL expression and the amount of stromal proliferation (desmoplasia), suggesting ATGL might mediate a desmoplastic response.

Cancer cells reprogram their metabolic pathways to meet increased demand for proliferation (14). One source of energy is lipids and altered lipid metabolism in oncogenesis has been studied extensively over the past decade. Cancer cells mostly depend on endogenous de novo synthesis for fatty acids, as evidenced by increased activity of intracellular enzymes involved in lipogenesis such as ATP citrate lyase, acetyl-CoA carboxylase and fatty acid synthase (14-16). Lipid metabolism in PDAC has not been studied in the human population. However, lipids are likely to be an important source of energy for PDAC tumor cells. Human PDAC cell lines incubated in the presence oleic and linoleic acid demonstrated increased proliferative rates (17), which could be oncogenic via an increase in reactive oxygen species (18). Philip et al. showed pancreatic tissue from mice 
that were fed a high-fat diet demonstrated increased oncogenic KRAS activity and accelerated pancreatic intraepithelial neoplasia development compared to mice on a low-fat diet, suggesting that dietary lipids may contribute to pancreatic cancer (19). Gnerlich et al. found increased ATGL expression in both peritumoral and tumor-free distant fat in obese patients with breast cancer, suggesting that ATGL might be implicated in how obesity increases the risk for breast cancer (10). Our study is the first to demonstrate increased ATGL expression within tumor cells of PDAC in overweight patients $\left(\mathrm{BMI}>25 \mathrm{~kg} / \mathrm{m}^{2}\right)$.

Additionally, this is also the first study to demonstrate an association between ATGL expression in tumor cells of PDAC and intratumoral stromal content in a human population. Histopathologically, PDAC consists of malignant glands infiltrating into fibrotic stroma composed mostly of extracellular matrix, which consists of type 1 collagen, fibronectin, hyaluronan and proteoglycans (20). Pancreatic stellate cells (PSCs) are resident cells of the pancreas, comprise approximately $5 \%$ of the pancreatic parenchyma (21) and have the important function of maintaining the balance of extracellular matrix synthesis and degradation (22). PSCs undergo a phenotypic transformation from a quiescent state to a myofibroblast-like state during times of pancreatic injury in response to stressors such as ethanol, oxidants and various cytokines (21-24). The results of our study suggest that ATGL might mediate an increase in tumor stroma, possibly by increasing free fatty acid content in the tumor microenvironment, thereby contributing to the phenotypic change of PSCs into an extracellular matrixsecreting state.

In summary, obesity is a well-established risk factor for the development PDAC. However, the pathophysiology of how increased adiposity increases the risk of PDAC is currently not well understood. Our results suggest that increased ATGL expression is associated with increased adiposity and stromal proliferation in patients with PDAC, making it a possible key protein in how obesity increases the risk of PDAC. Further studies to elucidate the role of ATGL in PDAC development and progression are warranted.

\section{References}

1 Gillen S, Schuster T, Meyer Zum Buschenfelde C, Friess H and Kleeff J: Preoperative/neoadjuvant therapy in pancreatic cancer: a systematic review and meta-analysis of response and resection percentages. PLoS Med 7: e1000267, 2010.

2 Malka D, Hammel P, Maire F, Rufat P, Madeira I, Pessione F, Levy P and Ruszniewski: Risk of pancreatic adenocarcinoma in chronic pancreatitis. Gut 51: 849-852, 2002.

3 Yu A, Woo SM, Joo J, Yang HR, Lee WJ, Park SJ and Nam BH: Development and validation of a prediction model to estimate individual risk of pancreatic cancer. PloS one 11: e0146473, 2016.
4 Zheng Z, Zheng R, He Y, Sun X, Wang N, Chen T and Chen W: Risk factors for pancreatic cancer in China: A multicenter casecontrol study. J Epidemiol 26: 64-70, 2016.

5 Bosetti C, Rosato V, Li D, Silverman D, Petersen GM, Bracci PM, Neale RE, Muscat J, Anderson K, Gallinger S, Olson SH, Miller AB, Bas Bueno-de-Mesquita H, Scelo G, Janout V, Holcatova I, Lagiou P, Serraino D, Lucenteforte E, Fabianova E, Ghadirian P, Baghurst PA, Zatonski W, Foretova L, Fontham E, Bamlet WR, Holly EA, Negri E, Hassan M, Prizment A, Cotterchio M, Cleary S, Kurtz RC, Maisonneuve P, Trichopoulos D, Polesel J, Duell EJ, Boffetta P and La Vecchia C: Diabetes, antidiabetic medications, and pancreatic cancer risk: an analysis from the International Pancreatic Cancer Case-Control Consortium. Ann Oncol 25: 2065-2072, 2014.

6 Silverman DT, Swanson CA, Gridley G, Wacholder S, Greenberg RS, Brown LM, Hayes RB, Swanson GM, Schoenberg JB, Pottern LM, Schwartz AG, Fraumeni JF and Hoover RN: Dietary and nutritional factors and pancreatic cancer: a case-control study based on direct interviews. J Natl Cancer Inst 90: 1710-1719, 1998.

7 Arslan AA, Helzlsouer KJ, Kooperberg C, Shu XO, Steplowski E, Bueno-de-Mesquita HB, Fuchs CS, Gross MD, Jacobs EJ, Lacroix AZ, Petersen GM, Stolzenberg-Solomon RZ, Zheng W, Albanes D, Amundadottir L, Bamlet WR, Barricarte A, Bingham SA, Boeing H, Boutron-Ruault MC, Buring JE, Chanock SJ, Clipp S, Gaziano JM, Giovannucci EL, Hankinson SE, Hartge P, Hoover, RN, Hunter DJ, Hutchinson A, Jacobs KB, Kraft P, Lynch SM, Manjer J, Manson JE, McTiernan A, McWilliams RR, Mendelsohn JB, Michaud DS, Palli D, Rohan TE, Slimani N, Thomas GT, Jonneland A, Tobias GS, Trichopoulos D, Virtamo J, Wolpin BM, Yu K, Zeleniuch-Jacquotte A and Patel AV: Anthropometric measures, body mass index, and pancreatic cancer: a pooled analysis from the Pancreatic Cancer Cohort Consortium (PanScan). Arch Intern Med 170: 791-802, 2010.

8 Mathur A, Zyromski NJ, Pitt HA, Al-Azzawi H, Walker JJ, Saxena R and Lillemore, KD: Pancreatic steatosis promotes dissemination and lethality of pancreatic cancer. J Am Coll Surg 208: 989-994, 2009.

9 Nomura DK, Long JZ, Niessen S, Hoover HS, Ng SW and Cravatt BF: Monoacylglycerol lipase regulates a fatty acid network that promotes cancer pathogenesis. Cell 140: 49-61, 2010.

10 Gnerlich JL, Yao KA, Fitchev PS, Goldschmidt RA, Bond MC, Cornwell $\mathrm{M}$ and Crawford SE: Peritumoral expression of adipokines and fatty acids in breast cancer. Ann Surg Oncol 20(Suppl 3): S731-738, 2013.

11 Doll JA, Stellmach VM, Bouck NP, Bergh AR, Lee C, Abramson LP,Cornwell ML, Pins MR, Borensztajn J and Crawford SE: Pigment epithelium-derived factor regulates the vasculature and mass of the prostate and pancreas. Nat Med 9: 774-780, 2003.

12 Food, Nutrition, Physical Activity, and the Prevention of Cancer: a Global Perspective. Washington DC: World Cancer Research Fund/American Institute for Cancer Research, 2007.

13 Preziosi G, Oben JA and Fusai G: Obesity and pancreatic cancer. Surg Oncol 23: 61-71, 2014.

14 Cairns RA, Harris IS and Mak TW: Regulation of cancer cell metabolism. Nat Rev Cancer 11: 85-95, 2011.

15 Tennant DA, Duran RV and Gottlieb E: Targeting metabolic transformation for cancer therapy. Nat Rev Cancer 10: 267-277, 2010 . 
16 Piyathilake CJ, Frost AR, Manne U, Bell WC, Weiss H, Heimburger DC and Grizzle WE: The expression of fatty acid synthase (FASE) is an early event in the development and progression of squamous cell carcinoma of the lung. Hum Pathol 31: 1068-1073, 2010.

17 Wang F, Kumagai-Braesch M, Herrington MK, Larsson J and Permert J: Increased lipid metabolism and cell turnover of $\mathrm{MiaPaCa} 2$ cells induced by high-fat diet in an orthotopic system. Metabolism 58: 1131-1136, 2009.

18 Pierre AS, Minville-Walz M, Fevre C, Hichami A, Gresti J, Pichon L, Bellenger J, Bellenger J, Ghiringheli F, Narce M and Rialland M: Trans-10, cis-12 conjugated linoleic acid induced cell death in human colon cancer cells through reactive oxygen species-mediated ER stress. Biochim Biophys Acta 1831: 759768, 2013.

19 Philip B, Roland CL, Daniluk J, Liu Y, Chatterjee D, Gomez SB, Ji B, Huang H, Wang H, Fleming JB, Logsdon CD and CruzMonserrate Z: A high-fat diet activates oncogenic KRAS and COX2 to induce development of pancreatic ductal adenocarcinoma in mice. Gastroenterology 145: 1449-1458, 2013.
20 Chu GC, Kimmelman AC, Hezel AF and DePinho RA: Stromal biology of pancreatic cancer. J Cell Biochem 101: 887-907, 2007.

21 Vonlaufen A, Phillips PA, Yang L, Xu Z, Fiala-Beer E, Zhang $\mathrm{X}$, Pirola RC, Wilson JS and Apte MV: Isolation of quiescent human pancreatic stellate cells: a promising in vitro tool for studies of human pancreatic stellate cell biology. Pancreatology 10: 434-443, 2010.

22 Apte MV, Pirola RC and Wilson JS: Pancreatic stellate cells: a starring role in normal and diseased pancreas. Front Physiol 3: 344, 2012.

23 Apte MV, Wilson JS, Lugea A and Pandol SJ: A starring role for stellate cells in the pancreatic cancer microenvironment. Gastroenterology 144: 1210-1219, 2013.

24 Apte MV and Wilson JS: Dangerous liaisons: pancreatic stellate cells and pancreatic cancer cells. J Gastroenterol Hepatol 27(Suppl 2): 69-74, 2012.

Received November 22, 2016

Revised December 12, 2016

Accepted December 16, 2016 